
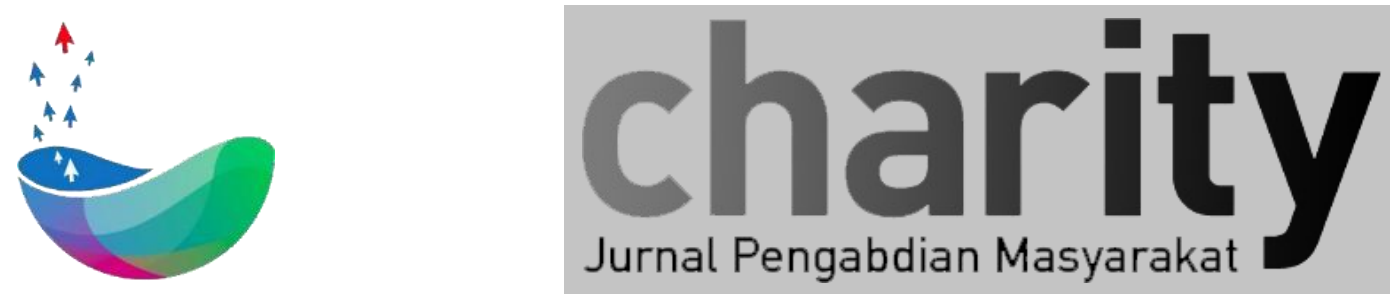

\title{
Pembuatan Website SMA Pesantren Datok Sulaiman Palopo Sulawesi Selatan
}

Eko Darwiyanto ${ }^{1}$, Moch Arif Bijaksana ${ }^{2}$, Aulia Khemas $\mathrm{H}^{3}$, Andi Annisa Shalsa Hardiyanti ${ }^{4}$, Muhammad Faridz Setiawan ${ }^{5}$

${ }^{1}$ Informatika, Fakultas Informatika, Universitas Telkom

${ }^{2}$ Informatika, Fakultas Informatika, Universitas Telkom

${ }^{3}$ Informatika, Fakultas Informatika, Universitas Telkom

${ }^{4}$ Teknologi Informasi, Fakultas Informatika, Universitas Telkom

5 Teknologi Informasi, Fakultas Informatika, Universitas Telkom

* ekodarwiyanto@telkomuniversity.ac.id, arifbijaksana@telkomuniversity.ac.id, auliakhamas@telkomuniversity.ac.id,

annisashalsa@student.telkomuniversity.ac.id, mfaridzsetiawan@telkomuniversity.ac.id

\section{INFO ARTIKEL}

Diterima 03 Februari 2021

Direvisi 20 Februari 2021

Disetujui 28 Agustus 2021

Tersedia Online 31 Agustus 2021

Keyword: SMA pesantren Datok Sulaiman, pembuatan website.

\begin{abstract}
ABSTRAK
SMA Pesantren Datok Sulaiman Palopo Sulawesi Selatan berdiri sejak 1982. Hingga kini banyak alumninya yang tersebar di berbagai daerah, terserap di berbagai PTN favorit, dan beberapa di antaranya telah bekerja. SMA ini hingga semester genap 2019/2020 belum memiliki website sekolah. Web sekolah sangat bermanfaat untuk media penyebaran informasi sekolah pada masyarakat, orang tua, dan siswa sekolah, di samping untuk bapak ibu guru, dinas pendidikan dan pihak-pihak terkait lainnya. Mahasiswa Teknologi Informasi Fakultas Informatika Universitas Telkom terpanggil untuk membuatkan websitenya, di bawah arahan dosen pembimbing. Memanfaatkan portal mysh.id, akhirnya dapat dibuat website smapesantrendatoksulaiman.mysch.id.
\end{abstract}

Korespondensi:

Direktorat Penelitian dan Pengabdian Masyarakat, Universitas Telkom

Jl. Telekomunikasi No. 1, Terusan Buah Batu, Bandung, 40257

Indonesia

E-mail : charity@telkomuniversity.ac.id

ORCID ID: 0000-0003-4805-9733

Penulis Pertama: Eko Darwiyyanto

https://doi.org/10.25124/charity.v4i2

Paper_reg_number xxx @ The Authors. Published by Directorate of Research and Community Service, Telkom

University.

This is an open access article under the xxx license (https://creativecommons.org/licenses/xxx) 


\section{Pendahuluan}

Undang-undang No 14 Tahun 2008, menyebutkan bahwa informasi publik adalah informasi yang dihasilkan, disimpan, dikelola, dikirim, dan/ atau diterima oleh suatu badan publik yang berkaitan dengan penyelenggara dan penyelenggaraan negara dan/ atau penyelenggara dan penyelenggaraan badan publik lainnya yang sesuai dengan Undang-Undang ini serta informasi lain yang berkaitan dengan kepentingan publik.

Badan publik adalah lembaga eksekutif, legislatif, yudikatif, dan badan lain* yang fungsi dan tugas pokoknya berkaitan dengan penyelenggaraan negara, yang sebagian atau seluruh dananya bersumber dari anggaran pendapatan dan belanja negara dan/ atau anggaran pendapatan dan belanja daerah, atau organisasi nonpemerintah sepanjang sebagian atau seluruh dananya bersumber dari anggaran pendapatan dan belanja negara dan/ atau anggaran pendapatan dan belanja daerah, sumbangan masyarakat, dan/ atau luar negeri. [1]

Badan Publik harus membangun dan mengembangkan sistem informasi dan dokumentasi untuk mengelola Informasi Publik secara baik dan efisien sehingga dapat diakses dengan mudah.

SMA Pesantren Datok Sulaiman berdiri sejak tahun 1982, adalah termasuk organisasi non pemerintah yang sebagian dananya bersumber dari APBN atau APBD, juga sumbangan masyarakat. Hingga semester genap 2019/2020, SMA tersebut belum memiliki website untuk memberikan informasi yang diperlukan pada publik.

\section{Permasalahan dan solusi yang ditawarkan}

SMA Pesantren Datok Sulaiman belum memiliki website sekolah. Penyampaian informasi kepada masyarakat masih menggunakan cara yang sederhana sehingga menjadi kurang efektif. Dengan adanya permasalahan tersebut maka tim ingin mengusulkan sebuah website sekolah.

Tujuan dari pembuatan website sekolah adalah untuk menghasilkan website SMA Pesantren Datok Sulaiman agar masyarakat luas dapat memperoleh informasi dengan mudah dan terperinci tanpa harus datang ke instansi.

Manfaat website sekolah untuk tenaga pendidikan:

1. Sekolah mempunyai data data profil siswa yang akurat.

2. Membantu siswa dalam berkreasi.

3. Menampilkan profil sekolah yang uptdate.

4. Terjalinnya Interaksi antar siswa Guru dan siswa yang tidak terbatas dengan ruang dan waktu.

5. Mengenalkan Profil sekolah secara umum bahkan dunia.

6. Menyediakan sarana belajar bagi siwa yang tidak terbatas dengan ruang dan waktu.

Manfaat website sekolah bagi Masyarakat:

1. Masyarakat Bisa mengakses data data tentang sekolah tanpa harus datang ke sekolah.

2. Melihat perkembangan kemajuan sekolah.

3. Mengamati kegiatan kegiatan sekolah. 
4. Bisa di jadikan referensi dan rujukan untuk memilih sekolah yang benar benar berkualitas.

Manfaat website sekolah bagi Siswa :

1. Melihat informasi - informasi terbaru dari sekolah.

2. Mengakses Materi materi pelajaran yang ada disekolah dan tak terbatas.

3. Belajar Tes Pengerjaan Soal soal pelajaran untuk mengasah kemampuan.

4. Mempunyai tempat untuk Menyalurkan kreasi di web sekolah.

Luaran Abdimas berupa website SMA Pesantren Datok Sulaiman,

Palopo, Sulawaesi Tengah, dan videonya serta paper pengabdian masyarakat di jurnal pengabdian masyarakat.

\section{Metode Pelaksanaan}

Dalam proses pembuatan website, tim mengikuti tahapan aliran proses yang disebutkan oleh Pressman dalam buku Software Engineeringnya:

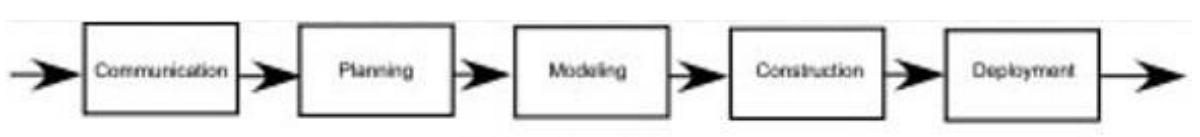

(a) Inear process fiow

Gambar 1. Linear Process Flow [2]

Komunikasi dengan Client diperlukan untuk memahami kebutuhan Client. Komunikasi dapat dilakukan melalui email, atau chatting Whatsapp, atau pesan melalui mahasiswa yang dekat dengan pihak sekolah. Tim juga melaporkan progres dari prototipe website setiap minggu dan berdiskusi jika ada hal yang kurang memuaskan client.

Di tahap planning, setelah berkomunikasi dengan pihak sekolah, tim mengatur diri untuk mengerjakan aktivitas-aktivitas yang diperlukan, menentukan $P I C$-nya, menentukan jadwal kegiatan, dan mempersiapkan alat dan bahan yang diperlukan.

Adalah domain mysch.id, dikembangkan oleh pemiliknya, untuk memfasilitasi sekolah-sekloah swasta yang belum memiliki web untuk membuat website mereka dengan cara yang sederhana. Fitur-fitur berikut disediakan oleh mysch.id :

\begin{tabular}{|llll|}
\hline Dashboard CMS & -Responsive Design & -SEO Friendly & -Email Sesuai Domain \\
Sambutan KepSek & -Menu / Halaman & -Berita Sekolah & -Galeri Foto \\
Slideshow & -Polling & -Download File & -Kontak \\
Youtube Video & -Custom HTML & -Silabus & -Materi \\
Kalender Akademik & -Data Guru & -Data Staff & -Data Alumni \\
Tata Letak & -Tema Desain & -Logo \& Icon & -Konsultasi \\
\hline
\end{tabular}

Gambar 2. Fitur mysch.id [3] 


\section{Hasil dan Pembahasan}

Website dan kontennya telah diupload ke mysch.id dengan menggunakan nama sekolah, sehingga URLnya adalah : http://smapesantrendatoksulaiman.mysch.id. Halaman home menampilkan slide show masjid, gedung tiga lantai SMA, suasana belajar di kelas dan kegiatan ekstra kurikuler sekolah.

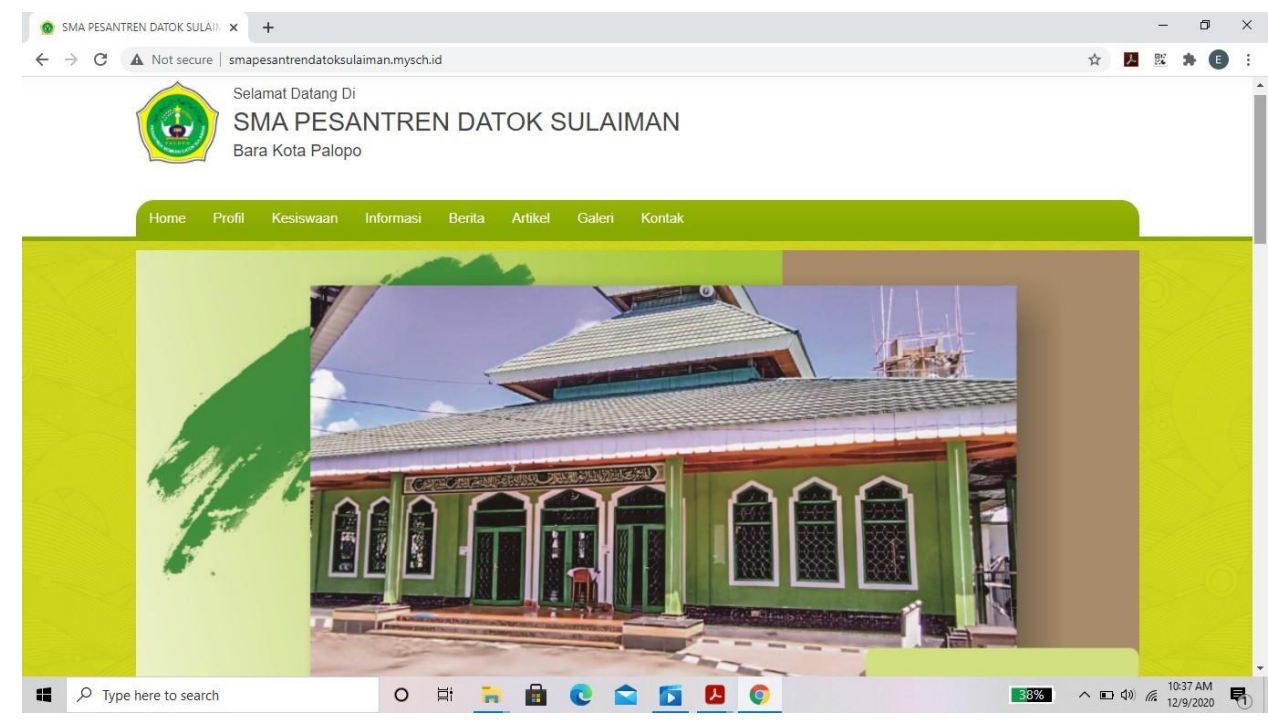

Gambar 3. Tampilan halaman Home

Tampilan-tampilan antarmuka yang lain selengkapnya dapat dilihat di alamat web tersebut.

\section{Kesimpulan}

Website telah dihasilkan. Beberapa keunggulannya adalah sebagai berikut:

1. Data website yang valid karena data yang diterima langsung dari client.

2. Sebagai media informasi sekolah bagi warga sekolah dan masyarakat.

3. Website yang dapat diakses oleh masyarakat umum.

4. Sebagai media promosi bagi sekolah.

Belum puas dengan semua fitur yang disediakan mysch.id, website sekolah ini masih dapat disempurnakan lebih jauh. 


\section{DAFTAR PUSTAKA}

[1] Undang-undang No 14 Tahun 2008. Available:

https://www.hukumonline.com/pusatdata/detail/28065/undangundang-nomor-14-tahun2008

[2] Roger S Pressman, "Software Engineering, a practitioner approach" 7/e. McGrawHill, 2009.

[3] https://www.mysch.id/ diakses 11 Desember 2020 